\title{
Roteiro geoturístico no centro da cidade de São Paulo
}

\author{
Wilian Carlos Batista Augusto ${ }^{1}$ \\ Dept. de Mineralogia e Geotectônica, Instituto de Geociências- \\ USP. Rua do Lago n. 562, Butantã,São Paulo. \\ ${ }^{1}$ wilian_augusto@yahoo.com.br \\ Eliane Aparecida Del Lama² \\ Dept. de Mineralogia e Geotectônica, Instituto de Geociências- \\ USP. Rua do Lago n. 562, Butantã,São Paulo. \\ edellama@usp.br
}

\begin{abstract}
GEOTOURISTIC WALK IN DOWNTOWN SÃO PAULO CITY. This paper proposes a geotouristic itinerary in downtown São Paulo city, visiting several historical and cultural monuments of stone constitution. The stone, either for use in construction of buildings as material for construction of monuments, has an ancient usage, due its durability and resistance that can be seen in numberless monuments around the world. It is still widely used, especially for the quality and diversity of dimension stone currently extracted. The association of stone monuments with cultural/touristics aspects is an excellent approach for dissemination of Geosciences, since it takes advantage of its attractive historical and cultural relationship with its constitution, allowing a link between them and the geological knowledge. The rocks used in monuments may be related to historic and economic evolution of the city, the architectural style of each era and the suitability of each rock on the various uses for building. In this paper it is proposed a walk in 15 monuments in the downtown of São Paulo city, visit the following monuments: A Menina e o Bezerro, Amor Materno, Depois do Banho, Fonte Monumental, O Índio Caçador, Camões, Cervantes, Chopin, Dante Alighieri, Göethe, Mário de Andrade, Obelisco da Memória, Guanabara, Antônio Carlos Gomes and Mãe Preta. The utilization of geotouristic walk can be an efficient way to divulge the Geosciences. It is a fairly common practice in Europe that is emerging in Brazil so promising. It is a simple, easy and cheap activity and it can be done by everyone. Citation: Augusto W. C. B., Lama E. A. D. 2010. Roteiro geoturístico no centro da cidade de São Paulo. Terræ Didatica, 7(1):18-29<http://www.ige.unicamp.br/terraedidatica/>
\end{abstract}

\section{KEYWORDS Geotouristic walk, stone monuments, rock, weathering.}

RESUMO Este artigo propõe um roteiro geoturístico pelo centro da cidade de São Paulo, com visita à diversos monumentos histórico-culturais de constituição pétrea. A pedra, tanto para uso em construção de edificações como material para confecção de monumentos, tem utilização milenar devido a sua durabilidade e resistência, como pode ser comprovado em monumentos espalhados pelo mundo. Ainda hoje é largamente utilizada, principalmente pela qualidade e grande diversidade das rochas ornamentais atualmente extraídas. Os monumentos de composição pétrea constituem-se num excelente canal para divulgação das Geociências, uma vez que se aproveita de seus atrativos histórico-culturais em relação com a sua constituição, permitindo um elo entre eles e os conhecimentos geológicos. As rochas empregadas nos monumentos podem ser relacionadas à evolução histórica e econômica da cidade, ao estilo arquitetônico de cada época e à adequabilidade de cada rocha nas várias utilizações da construção civil. O roteiro proposto agrupa 15 monumentos no centro histórico da cidade de São Paulo, visitando os seguintes monumentos: A Menina e o Bezerro, Amor Materno, Depois do Banho, Fonte Monumental, O Índio Caçador, Camões, Cervantes, Chopin, Dante Alighieri, Göethe, Mário de Andrade, Obelisco da Memória, Guanabara, Antônio Carlos Gomes e Mãe Preta. A utilização de roteiros geoturísticos pode ser uma forma bastante eficiente de divulgar as Geociências. É uma prática bastante comum na Europa, que começa a surgir no Brasil de forma promissora. É um roteiro simples, fácil e barato que pode ser feito por pessoas de todas as idades e formações.

PALAVRAS-CHAVE Roteiro geoturístico, monumentos pétreos, rocha, alteração. 


\section{Introdução}

Roteiros turístico-geológicos podem ser uma maneira eficaz de divulgação das Geociências, já que no contexto de uma atividade de lazer, diferentes tipos de rochas podem ser apresentadas a um público leigo, discutindo sua formação, constituição e visualização de diferentes formas de alteração da pedra e como qualquer outro material há cuidados especiais na sua conservação. A depender do público, estas informações podem ser mais ou menos aprofundadas. Com este objetivo, elaborouse um roteiro no centro velho de São Paulo com informações e constituição material de 15 monumentos. As figuras representam um resumo informativo de cada monumento e por si só constituem o roteiro de visitação.

A utilização de materiais pétreos é muito antiga, remonta ao Plioceno, com registros dos primeiros seixos lascados em torno de 3.000.000 A.P., com fins de utensílios e como armas.

O manuseio dos materiais foi tão importante que acabou nomeando a história da civilização: Idade da Pedra (Paleolítico, Mesolítico e Neolítico), Idade Calcolítica, Idade do Bronze e Idade do Ferro.

Durante muito tempo a pedra lascada foi o material mais usado para confecção de utensílios e armas, já que era um material abundante, resistente e durável.

A pedra foi utilizada na primeira expressão artística do homem primitivo: as pinturas rupestres do período paleolítico. Exemplos excepcionais desta arte são encontrados na Caverna de Altamira (Espanha), Caverna de Lascaux (França) e Parque Nacional da Serra da Capivara (PI, Brasil). Além da utilização da pedra como suporte da pintura, a tinta foi fornecida por minerais e rochas como calcário, hematita, pirolusita e argilominerais. As pinturas rupestres foram os primeiros registros de como viviam os seres humanos, já que a escrita ainda não havia sido inventada.

Em épocas mais recentes, a partir de $7.000 \mathrm{aC}$, a pedra é utilizada em expressões religiosas, na era dos megalitos europeus, já no período neolítico. Os megalitos constituem as primeiras formas de arquitetura monumental da pré-história. Exemplos dos megalitos mais famosos: Alinhamento de Kermario-Carnac (França), Stonehenge (Inglaterra), Cremeleque dos Almendres (Portugal) e Dólmens de Antequera (Espanha).
No Egito, foram construídas as pirâmides. Não foram as primeiras construções, já que anteriormente foram utilizados adobes de lama e madeira, mas para os monumentos faraônicos escolheu-se um material mais durável: a pedra.

A primeira lei do mundo, o Código de Hammurabi, foi cunhada em um basalto em 1792-1750 aC.

Grandes monumentos foram construídos em pedra e permanecem até nossos dias: Partenon (Grécia), Coliseu (Itália), Muralhas de Adriano (Inglaterra), Pirâmides Maia (México), apenas para citar alguns exemplos.

Ainda hoje a pedra é muito utilizada na construção civil, sendo que o Brasil é um dos países que possui grande diversidade de rochas ornamentais.

E por suas características, a pedra é o principal material utilizado na confecção de monumentos.

O Brasil, por ser um país de colonização mais nova comparado com os países dos continentes africano, europeu e asiático, não possui monumentos de idade muito antiga. Os mais antigos estão localizados nas cidades que foram primeiramente colonizadas, como São Luís - MA, Olinda e Recife - PE, São Cristóvão - SE, Salvador - BA, Rio de Janeiro e Paraty - RJ, Ouro Preto e Congonhas do Campo - MG, e São Vicente - SP. Nestas cidades encontram-se adornos e edifícios dos séculos XVI eXVII, constituídos por granito, gnaisse, quartzito, xisto, pedra-sabão, entre outras.

A cidade de São Paulo, com os seus 457 anos de idade, em termos de ocupação urbana tem uma história muito recente. Apenas no final do século XIX a cidade começa a se desenvolver, expandindo o triângulo histórico formado pelas ruas Direita, São Bento e 15 de Novembro, área esta topograficamente mais elevada do centro de São Paulo. Com a chegada da ferrovia, o comércio prosperou muito devido à economia cafeeira. A partir de 1920 a periferia da cidade cresce exponencialmente e o centro verticalmente, com a construção dos primeiros arranha-céus. A ocupação histórica de São Paulo e um excelente registro fotográfico podem ser consultados em Pontes (2003).

São Paulo possui um rico acervo de monumentos, onde o mais antigo é o Obelisco da Memória, que fica localizado no Largo da Memória, implantado em 1814. Antigamente era conhecido como Pirâmide do Piques, e tem sua importância histórica por ter sido o local de chegada das tropas e onde se realizava um intenso comércio das mais variadas mercadorias. A partir daí, cruzava-se o ribeirão 
Anhangabaú e chegava-se ao triângulo histórico.

Os monumentos apresentados no presente roteiro geoturístico aqui proposto constituem-se em homenagens, pertencentes a uma política de embelezamento de ruas e parques que se deu principalmente a partir de 1920 .

A área de materiais pétreos e conservação de monumentos é ainda recente na área das Geociências, mas gradualmente o número de publicações está aumentando (Frascá 2003, Silva \& Roeser 2003, Del Lama 2006, Baptista Neto et al. 2006, Stern et al. 2006, Philipp \& Di Benedetti 2007, Reys et al. 2007, Del Lama 2008, Del Lama et al. 2008, Teixeira et al. 2008, Costa 2009).

Um roteiro turístico-geológico com enfoque em edifícios históricos no centro de São Paulo é encontrado em Stern et al. (2006).

A procedência das rochas de parte dos monumentos apresentados aqui é discutida em Del Lama et al. (2009). Os autores apontam que os granitos Itaquera e Cinza Mauá foram as principais rochas utilizadas tanto em monumentos como edifícios, sendo o primeiro mais utilizado no começo do século XX e o segundo foi mais utilizado a partir de 1940. A procedência de diversos outros tipos de rocha não está claramente registrada, sendo por isso especulativa sua origem.

O presente trabalho propõe um roteiro geológico e cultural, com a descrição de monumentos e estátuas do centro de São Paulo, do ponto de vista da rocha utilizada em sua confecção. A realização do roteiro e a discussão sobre a litologia e os tipos de alteração destas rochas, devido às ações intempéricas, poderia despertar a curiosidade de leigos, e então levá-los à busca por mais conhecimento dentro da área das Geociências, especificamente sobre rochas ornamentais e monumentos feitos de rocha, além dos aspectos culturais. As rochas empregadas podem ser relacionadas à evolução histórica e econômica da cidade, ao estilo arquitetônico de cada época e a adequabilidade de cada rocha nas várias utilizações da construção civil.

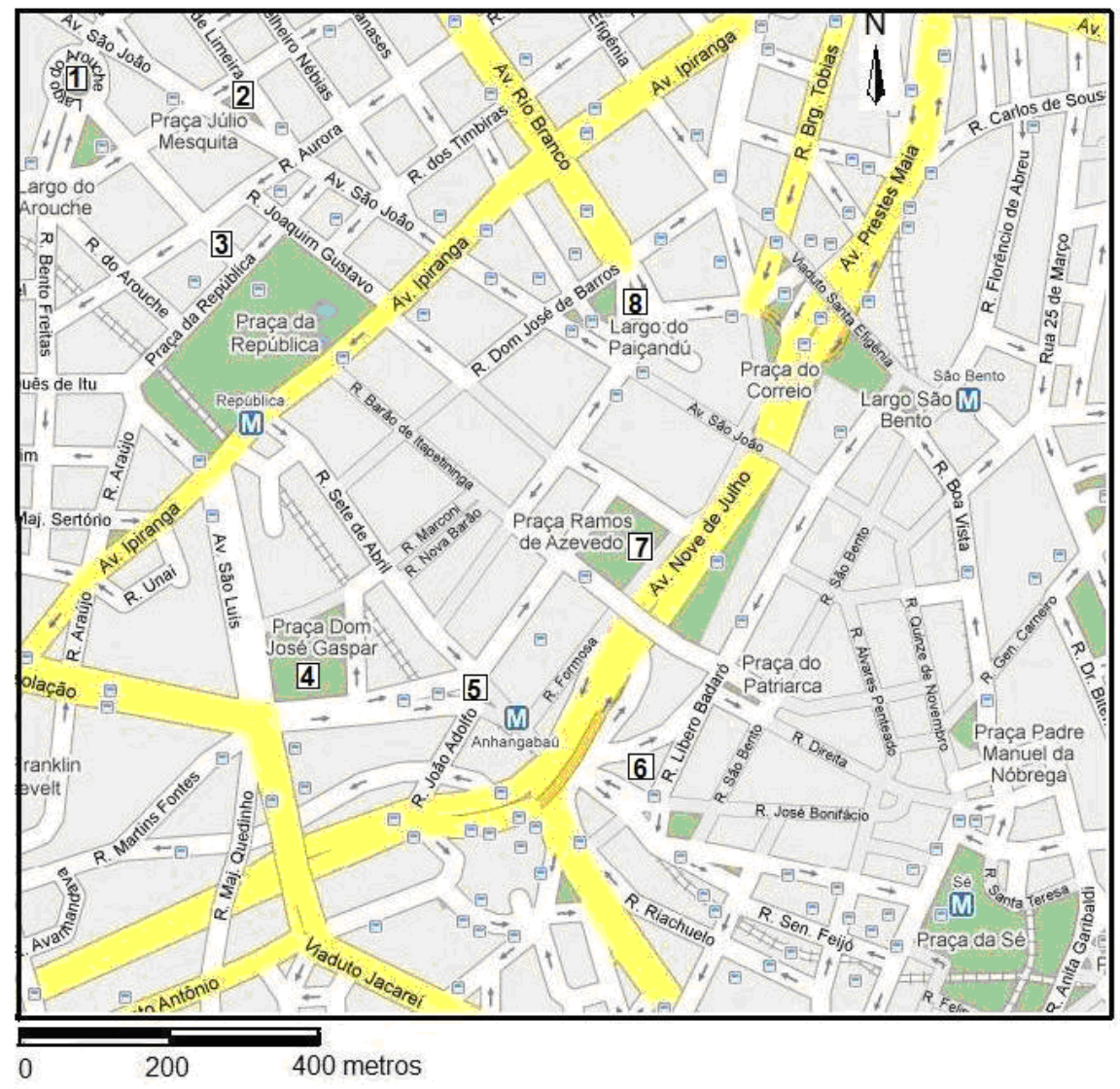

Monumentos:

1) A Menina e o Bezerro Amor Materno Depois do Banho

Fonte Monumental

3 O Índio Caçador

4 Camões

Cervantes

Chopin

Dante Alighieri

Goethe

Mário de Andrade

5 Obelisco da Memória

6. Guanabara

7 Antônio Carlos Gomes

8 Mãe Preta

Figura 1. Mapa do centro de São Paulo e a localização dos monumentos do roteiro (Extraído e modificado de http://www.spturismo.com/capital-interativo.htm) 
A Figura 1 mostra a localização dos monumentos que constam do presente roteiro pelo centro velho de São Paulo.

\section{Materiais pétreos e os monumentos}

Os monumentos abordados neste roteiro são constituídos por rochas e liga metálica, confeccionados entre 1814 a 1955.

O bronze, liga metálica composta de cobre e estanho, é muito apreciado na confecção de estátuas, por ser um material de boa trabalhabilidade e por apresentar uma resistência maior do que a do cobre puro. Seu inconveniente é que a sua oxidação provacada pelas águas das chuvas causa manchamentos, deixando na pedra subjacente dos monumentos uma coloração esverdeada.

Os monumentos confeccionados em bronze geralmente apresentam pedestal de pedra. Exemplos neste roteiro são: Depois do Banho, O Índio Caçador, Camões, Cervantes, Chopin, Göethe, Mário de Andrade, Antônio Carlos Gomes e Mãe Preta.

Rochas são agregados de um ou mais minerais, e classificam-se quanto a sua origem, em rochas sedimentares, ígneas e metamórficas.

Rochas sedimentares são formadas pelo acúmulo de sedimentos em bacias sedimentares, formando camadas, onde estes sedimentos sofreram processos de compactação e litificação. No quesito resistência mecânica estas rochas podem ser as mais frágeis. Sua forma de deposição em estratos (camadas) pode ocasionar futuros desplacamentos e, portanto são menos utilizadas na confecção de estátuas ou monumentos. Dentre as rochas sedimentares, os arenitos e calcários são as rochas mais utilizadas para esta finalidade, e foram utilizadas principalmente em monumentos europeus. No Brasil, há poucos monumentos em calcário. $\mathrm{O}$ monumento a Dante Alighieri é constituído por travertino, uma rocha carbonática, constituinte também do Edifício Matarazzo (atual Prefeitura), tendo sido importado da Itália. Monumentos em arenitos já são mais comuns, por exemplo, a fachada frontal do Teatro Municipal. Este arenito é proveniente do Grupo Itararé da Bacia do Paraná, e foi extraído de uma pedreira pertencente à área da Floresta Nacional de Ipanema em Iperó, SP (Del Lama et al. 2008). Como exemplos de edificações construídas em arenito em outra localidade pode ser citada as ruínas em São Miguel das Missões (RS).
Rochas ígneas são geradas pelo resfriamento e cristalização do magma (rochas plutônicas) ou da lava (rochas vulcânicas). Estas rochas são muito utilizadas para a construção de estátuas e monumentos, pois têm uma resistência mecânica alta devido a sua estrutura maciça e a estabilidade de seus minerais. Dentre as rochas ígneas, os granitos são as rochas mais utilizadas em esculturas. Os monumentos incluídos neste roteiro constituídos por estas rochas são: Amor Materno, Camões, Cervantes, Chopin, Depois do Banho, Göethe, Mário de Andrade, O Índio Caçador, Obelisco da Memória, Guanabara, Antônio Carlos Gomes e Mãe Preta. Além desses, muitas edificações no centro velho são constituídas por granito, por exemplo, a Igreja de São Bento, o Centro Cultural Banco do Brasil, o Shopping Light (Edifício Alexandre Mackenzie), o Antigo Tribunal da Alçada Civil, a Faculdade de Direito da USP, o Edifício Martinelli, a Biblioteca Municipal Mário de Andrade e a Catedral da Sé. Os granitos utilizados são provenientes da Grande São Paulo ou do interior do Estado, como por exemplo, Granito Itaquera, Granito Cinza Mauá, Granito Vermelho Capão Bonito, Granito Cinza Sorocaba, Granito Rosa Itupeva. As propriedades mecânicas dos diferentes granitos ornamentais paulistas são similares e sua utilização e escolha provavelmente deu-se pela abundância, proximidade da capital e o aspecto estético.

Rochas metamórficas são resultantes da transformação de rochas pré-existentes, ou seja, são geradas por mudanças de pressões e temperaturas que possibilitam o rearranjo em estado sólido de seus minerais. Gnaisses e mármores são as rochas metamórficas mais comumente utilizadas. Elas são também bastante resistentes e apreciadas como matéria prima de monumentos. A desvantagem na utilização deste tipo de rocha é devido a sua foliação, estruturas planares que ocorrem no interior da rocha, que pode originar planos preferenciais de quebra em estátuas e monumentos, assim como facilitar a percolação de águas meteóricas favorecendo sua alteração. Exemplos destas rochas no roteiro: A Menina e o Bezerro, Amor Materno, Fonte Monumental e Antônio Carlos Gomes.

$\mathrm{Nas}$ rochas que compõem os monumentos ocorrem alterações em diferentes formas. A degradação dos monumentos é um processo natural que acontece devido ao intemperismo, que pode ser de origem física, química ou biológica, que pode ser acelerada devido à ação antropogênica. 
O intemperismo físico ocorre devido à desagregação das rochas e tem causas mecânicas. $\mathrm{O}$ desgaste de superfícies devido ao atrito da rocha com o vento carregado de partículas de areia, ou a fragmentação da rocha devido a sua expansão e contração, que acontece em razão do aquecimento proveniente da energia solar, são exemplos de intemperismo físico. Desta forma, observa-se que, nos monumentos, o intemperismo físico pode provacar perda de partes, observando-se quinas quebradas, partes faltantes, etc. Rochas com estruturas orientadas como nas rochas metamórficas podem favorecer estas formas de intemperismo.

$\mathrm{O}$ intemperismo químico ocorre devido à decomposição dos minerais originais das rochas, que pode gerar minerais secundários (neoformados), ou lixiviar cátions e ânions (transportá-los em solução). Este tipo de intemperismo é mais observado em monumentos confeccionados com rochas calcárias ou mármores. Em monumentos, o intemperismo químico pode gerar alvéolos, manchas, pátina e concreção.

O intemperismo biológico ocorre devido à interferência dos seres vivos sobre os monumentos, como por exemplo, o crescimento de musgo em estátuas, ou até mesmo devido à presença de fezes de pombos. O aspecto estético mais relacionado a este tipo de intemperismo traduz-se na presença de manchas e consequente sujidade dos monumentos.

O intemperismo, seja químico, físico ou biológico desestabiliza os minerais primários das rochas tornando-os mais susceptíveis a alterações. A caracterização e a classificação dos tipos e formas de alteração e/ou degradação de rochas observados nos monumentos ou estátuas foram sistematizados por diversos autores, como Fitzner \& Heinrichs (2004), Henriques et al. (2005) e ICOMOS (2008).

A nomenclatura das formas de alteração utilizada no presente trabalho está de acordo com o apresentado em ICOMOS (2008), que divide as alterações em rochas de monumentos e estátuas em 5 grandes grupos: fissura e deformação, destacamento, feições induzidas por perda de material, alteração cromática e depósito, e colonização biológica. Estes grupos por sua vez são divididos em vários subgrupos, e serão descritos apenas os termos utilizados neste trabalho.

Fissura (Crack): Fenda contínua, visível a olho nu, como resultado da separação de uma parte em relação à outra.
Fratura (Fracture): Fratura é um tipo de fissura que atravessa totalmente um pedaço de rocha, atingindo de uma extremidade a outra.

Rompimento (Bursting): Perda de parte localizada da rocha devido à despressurização interna. Geralmente manifesta-se de forma irregular.

Alveolização (Alveolization): Formação de cavidades na superfície das rochas (alvéolos), que podem ter diferentes formatos e tamanhos, geralmente centimétricos, mas também podem ser métricos.

Perda de partes (Missing part): Espaços vazios onde existiam anteriormente partes de rocha. Protuberâncias como narizes ou dedos de esculturas são típicas porções faltantes.

Perfuração (Perforation): Um único ou uma série de furos superficiais, concavidades ou lacunas criados por uma ferramenta aguda ou por animais. As dimensões variam de milimétricas a centimétricas. Perfurações são mais profundas que largas e são feições penetrativas no corpo de rocha.

Alteração cromática (Discolouration): Mudança na cor original da rocha em pelo menos um de três parâmetros, sendo eles matiz, intensidade e saturação. Matiz corresponde ao componente mais predominante da cor (azul, verde, vermelho, etc.), intensidade corresponde à tonalidade, que varia de muito claro até muito escuro, e saturação corresponde à pureza da cor.

Depósito (Deposit): Acumulação de material exógeno de espessura variada. Alguns exemplos desses depósitos são borrifados de tinta ou argamassa, partículas de fuligem e partículas de poeira.

Eflorescência (Efflorescence): Material esbranquiçado, pulverulento, que pode ocorrer também como cristais alongados, geralmente sem coesão e comumente composto por sais solúveis, como por exemplo, halita $(\mathrm{NaCl})$, calcita $\left(\mathrm{CaCO}_{3}\right)$, barita $\left(\mathrm{BaSO}_{4}\right)$ e gipsita $\left(\mathrm{CaSO}_{4} \cdot 2 \mathrm{H}_{2} \mathrm{O}\right)$.

Grafitagem (Graffiti): Gravação, ou aplicação de tintas ou materiais similares, superficial. A maior parte do uso da grafitagem é devese a vandalismo, mas alguns têm valores históricos, estéticos e culturais, e deveriam ser conservados, como por exemplo, as celas do antigo prédio do DOPS em São Paulo, cujas 
paredes foram grafitadas pelos presos políticos que nelas estavam encarcerados.

Mancha (Staining): Um tipo de alteração cromática, de dimensões reduzidas e aspecto não atrativo.

Pátina (Patina): Modificação cromática de materiais resultante do envelhecimento natural ou artificial destes materiais, e que não envolve, na maioria dos casos, uma superfície de deterioração.

Sujidade (Soiling): Depósito de uma camada muito fina de partículas exógenas, como, por exemplo, a fuligem, gerando uma aparência suja na superfície da rocha.

\section{Roteiro geoturístico}

$\mathrm{Na}$ confecção do presente roteiro foram incluídos 15 monumentos.

As rochas constituintes desses monumentos, que são indicadas nas respectivas descrições, são mármores e gnaisses (rochas metamórficas), granitos (rochas ígneas) e travertino (rocha sedimentar carbonática), tanto em sua constituição propriamente, ou na sua base de sustentação, quando se tratar de monumentos em bronze.

Em geral, os monumentos apresentam algum grau de alteração e/ou depredação.

O percurso total perfaz aproximadamente 2 $\mathrm{km}$, a ser realizado a pé devido ao inconveniente do deslocamento em automóveis na área central, com um tempo mínimo estimado de 2 horas e paradas para observações e registro fotográfico.

Os monumentos do roteiro são: $A$ Menina e o Bezerro, Amor Materno, Depois do Banho, Fonte Monumental, OÍndio Caçador, Camões, Cervantes, Chopin, Dante Alighieri, Göethe, Mário de Andrade, Obelisco da Memória, Guanabara, Antônio Carlos Gomes e Mãe Preta.

\section{Ponto $\mathrm{n}^{0}$ 1: Largo de Arouche}

Durante a gestão do ex-prefeito de São Paulo Raymundo Duprat (1911-1914), várias estátuas foram adquiridas para embelezar praças e jardins paulistanos de empresas francesas, entre elas $A$ Menina e o Bezerro e Amor Materno.

Nesta parada observaremos 3 monumentos: $A$ Menina e o Bezerro (Fig. 2), Amor Materno (Fig. 3) e Depois do Banho (Fig. 4).

A Menina e o Bezerro - a estátua é composta por mármore apresentando princípio de alveolização. O pedestal é composto por biotita granito

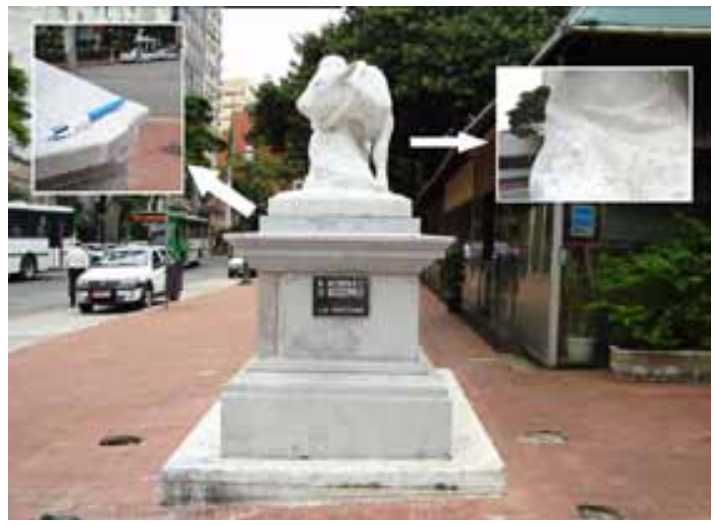

Figura 2. A Menina e o Bezerro. Autor: Pierre Christophe; Tipologia: Grupo escultório; Material: Mármore e pedestal de biotita granito, comercialmente conhecido por Granito Itaquera; Data de implantação: Cerca de 1922; Localização: Largo do Arouche; Localização anterior: Parque Anhangabaú (1914)

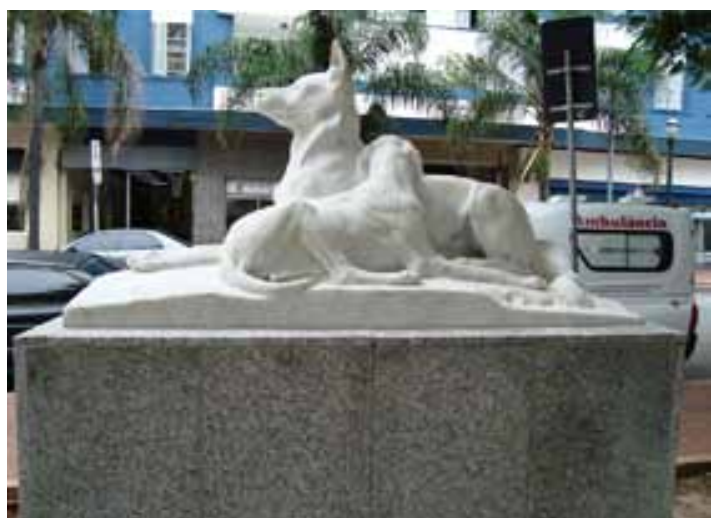

Figura 3. Amor Materno. Autor: Charles-Louis-Éugene Virion; Tipologia: Grupo escultório; Material: Mármore e pedestal de granito acinzentado com fenocristais de feldspato; Data de implantação: Entre 1911 e 1914; Localização: Largo do Arouche; Localização anteriores: Parque Anhangabaú (1914); Jardim da Luz (1922)

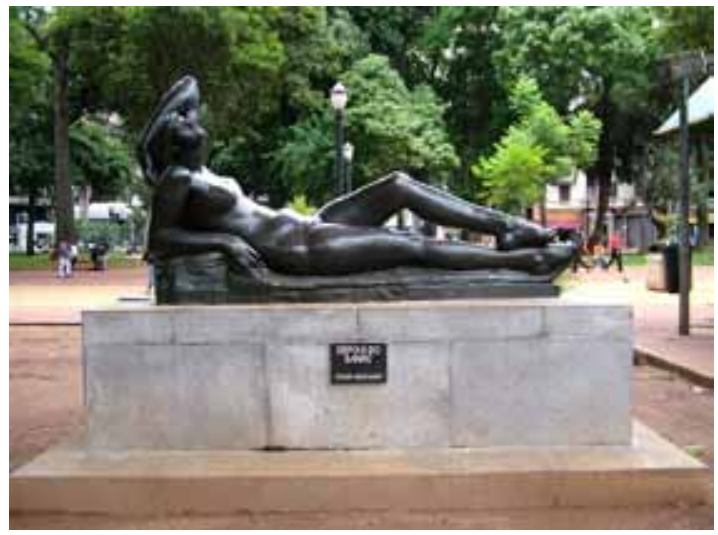

Figura 4. Depois do Banho. Autor: Victor Breecheret; Tipologia: Estátua; Material: Bronze e pedestal de biotita granito (Granito Itaquera); Data de implantação: Cerca de 1941; Localização: Largo do Arouche 
de coloração acinzentada, de granulometria média inequigranular e comercialmente conhecido como Granito Itaquera.

As formas de alteração observadas são: fissura, fratura, alveolização, perda de partes, perfuração, mancha e sujidade.

O pedestal possui perdas de partes na forma de algumas quinas quebradas e também perda de seu rejunte. Perfuração na estátua de mármore foi encontrada devido à atividade antrópica. Fissuras e fraturas também são encontradas. Fuligem e outras partículas atmosféricas podem ser transportadas pelo vento e sujar principalmente estátuas de mármore, que são mais susceptíveis devido a sua alvura.

No detalhe da Figura 2 observa-se a quina posterior esquerda do pedestal de granito quebrado e pequenas manchas na estátua de mármore.

Amor Materno - esta obra é composta por duas rochas diferentes: a estátua de mármore e o seu pedestal, recentemente colocado, de biotita granito porfirítico com estrutura de fluxo, de coloração acinzentada e com fenocristais de feldspato dispersos em uma matriz de granulação média, constituída por quartzo, feldspato e biotita. O pedestal anterior era constituído pelo Granito Itaquera. A estátua da cachorra, em mármore, estava com partes faltantes (as duas orelhas), que foram refeitas com resina. O super dimensionamento das orelhas na reconstituição apresenta-se desproporcional, destoando no monumento.

Não foi observado nenhum grau de alteração do tipo alveolização, que é um tipo de alteração muito comum para rochas carbonáticas. Sua superfície foi limpa recentemente, removendo a caiação a que o monumento foi submetido no passado. $\mathrm{O}$ pedestal composto por granito é muito recente, e não apresenta nenhum tipo de alteração, exceto sujidade.

Depois do Banho - confeccionada em bronze, tem sua base constituída pelo Granito Itaquera. As formas de alteração observadas foram: mancha e sujidade no granito e eflorescência no bronze.

\section{Ponto ${ }^{0}$ 2: Praça Júlio de Mesquita}

Neste ponto, é observada a Fonte Monumental, uma escultura em art noveau. O histórico deste monumento, implantado pela Prefeitura em 1927 para celebrar a construção da Praça Júlio de Mesquita na Avenida São João, mostra constantes depredações e furtos de adornos. Tentativas de

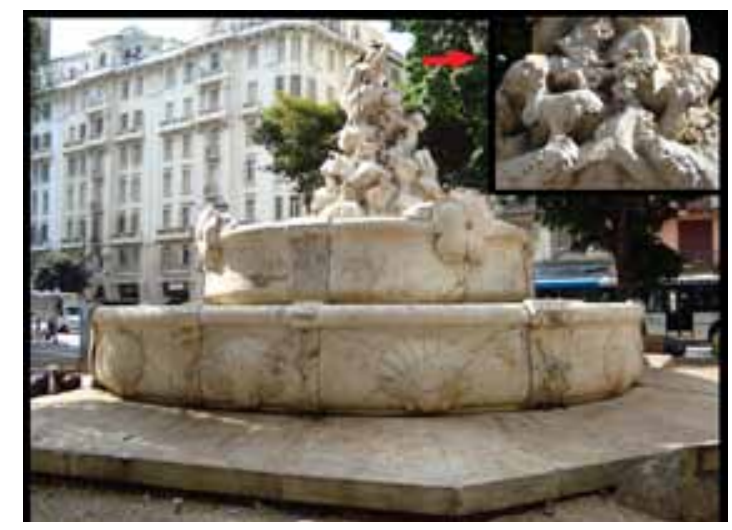

Figura 5. Fonte Monumental. Autor: Nicolina Vaz de Assis Pinto do Couto; Tipologia: Monumento; Material: Mármore; Data de implantação: 1927; Localização: Praça Júlio Mesquita

manter o projeto original da escultora Nicolina Vaz de Assis Pinto do Couto mostram-se infrutíferas.

A sua constituição em mármore sofre degradações naturais. A água da chuva solubiliza parte dos minerais carbonáticos transportando-os em solução, porém não de forma igual em toda a rocha, criando assim cavidades aleatórias no mármore como pode ser observado no detalhe da Figura 5. A alteração em forma de cavidades em rochas carbonáticas é conhecida como alveolização. Outras formas de alteração observadas: fissura, fratura, perda de partes, mancha, pichação (grafitagem) e sujidade.

O piso da Praça Júlio de Mesquita, constituído por ladrilho português, é original da época da construção, e mostra-se razoavelmente preservado, constituindo-se em um dos poucos locais da cidade em que isto ocorre.

\section{Ponto $\mathrm{n}^{0} 3$ : Praça da República/Avenida Vieira de Carvalho}

O Índio Caçador foi encomendado por Prestes Maia, prefeito de São Paulo entre maio de 1938 e novembro de 1945, e foi implantado em 1940. O detalhe da Figura 6 destaca resto de chiclete no pedestal, mas este não é o único problema em sua conservação já que marcas de pichação (grafitagem) e perda de partes também são bem visíveis nesta obra.

\section{Ponto $n^{0}$ 4: Praça Dom José Gaspar}

$\mathrm{Na}$ Praça Dom José Gaspar ocorre talvez a mais eclética aglomeração artística da cidade de São Paulo, com diversas estátuas que homenageiam várias culturas que ajudaram a construir esta cidade. As 


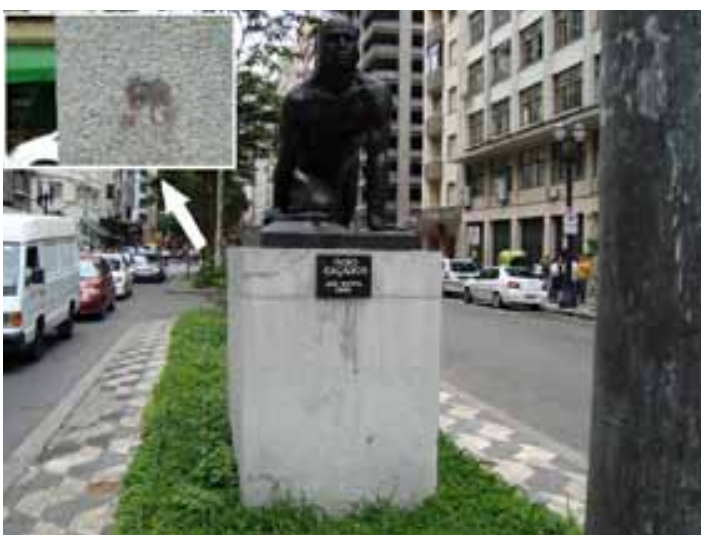

Figura 6. O Índio Caçador. Autor: João Batista Ferri; Tipologia: Estátua; Material: Bronze e pedestal de biotita granito (Granito Itaquera); Data de implantação: 1940; Localização: Avenida Vieira de Carvalho (canteiro central, próximo à Praça da República)

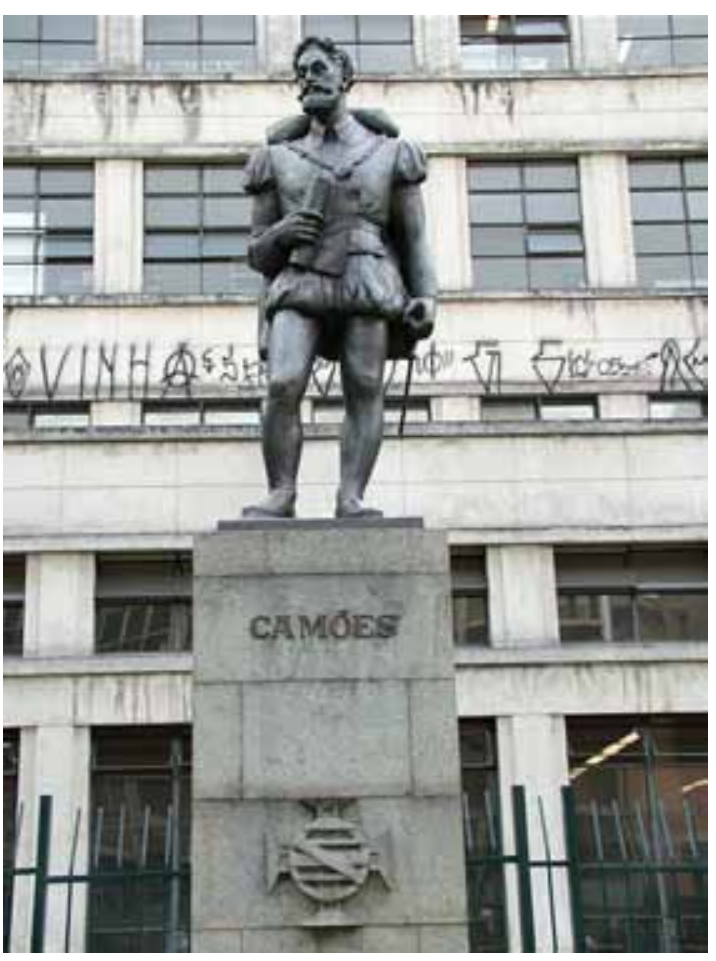

Figura 7. Camões. Autor: José Cucê; Tipologia: Estátua; Material: Bronze e pedestal em granito de coloração acinzentada e granulometria média e inequigranular, comercialmente conhecido como Cinza Mauá; Data de implantação: 1942; Localização: Praça Dom José Gaspar

estátuas de Camões (Fig. 7), Cervantes (Fig. 8), Chopin (Fig. 9), Dante Alighieri (Fig. 10) e Göethe (Fig. 11) homenageiam as comunidades de imigrantes portugueses, espanhóis, poloneses, italianos e alemães, respectivamente, implantadas entre 1942 a 1955.

A grande quantidade de pombas na Praça Dom

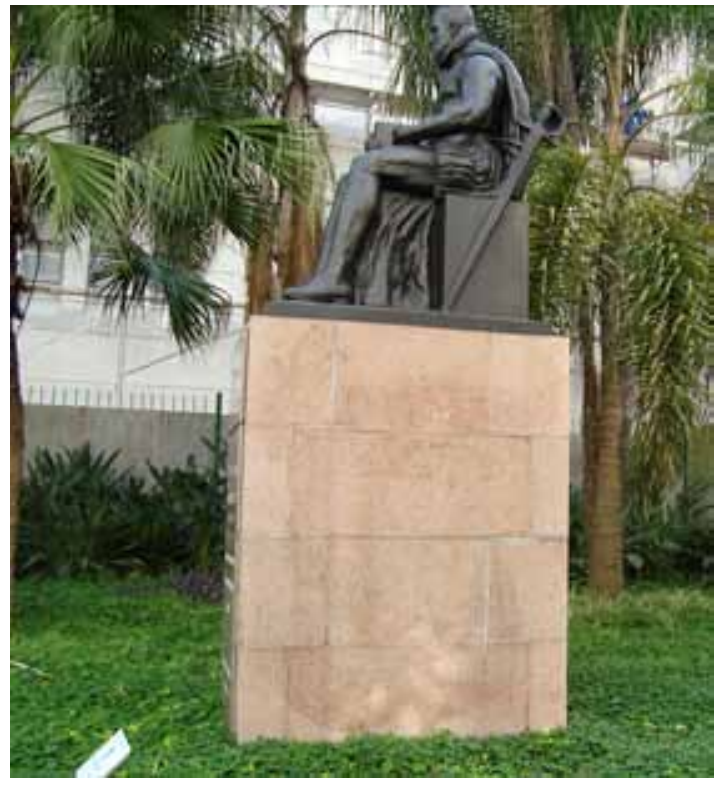

Figura 8. Cervantes. Autor: Rafael Galvez; Tipologia: Estátua; Material: Bronze e pedestal de granito vermelho com fenocristais de feldspato; Data de implantação: 1947; Localização: Praça Dom José Gaspar)

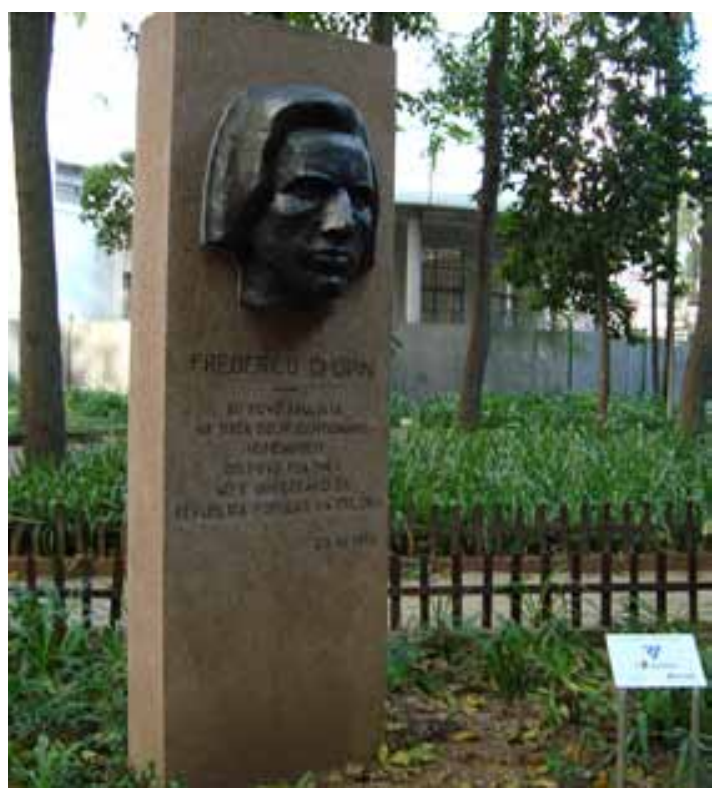

Figura 9. Chopin. Autor: Desconhecido; Tipologia: Máscara em Estela; Material: Máscara em bronze, com a efígie do compositor, aplicada a um suporte de granito vermelho porfirítico com fenocristais de feldspato; Data de implantação: 1954; Localização: Praça Dom José Gaspar

José Gaspar prejudica os monumentos lá instalados, devido à deposição de dejetos fecais, carecendo de limpezas periódicas.

Camões - foi doado à Prefeitura de São Paulo pela Casa de Portugal.

A obra está cercada por grade, o que não pode 


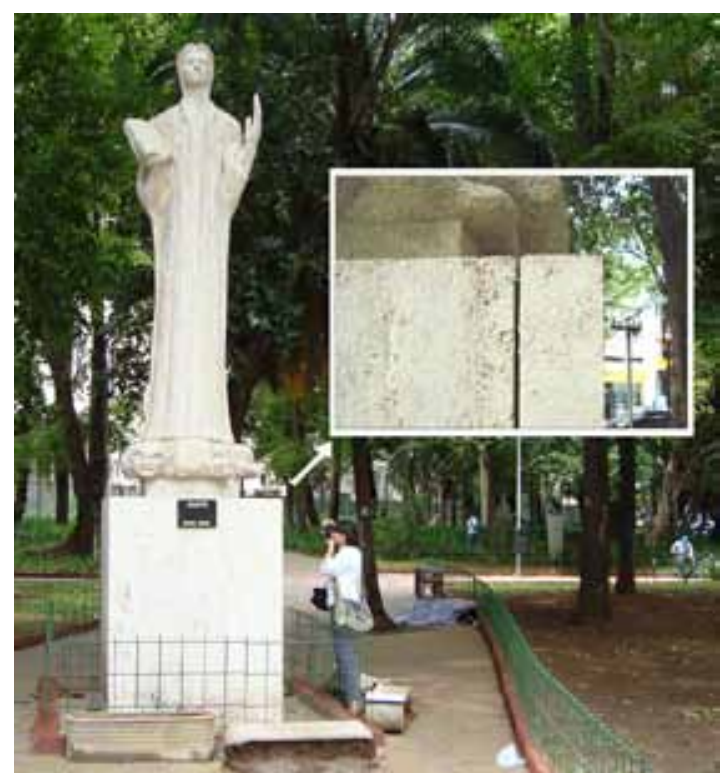

Figura 10. Dante Alighieri. Autor: Bruno Giorgi; Tipologia: Estátua; Material: Travertino; Data de implantação: 1955; Praça Dom José Gaspar

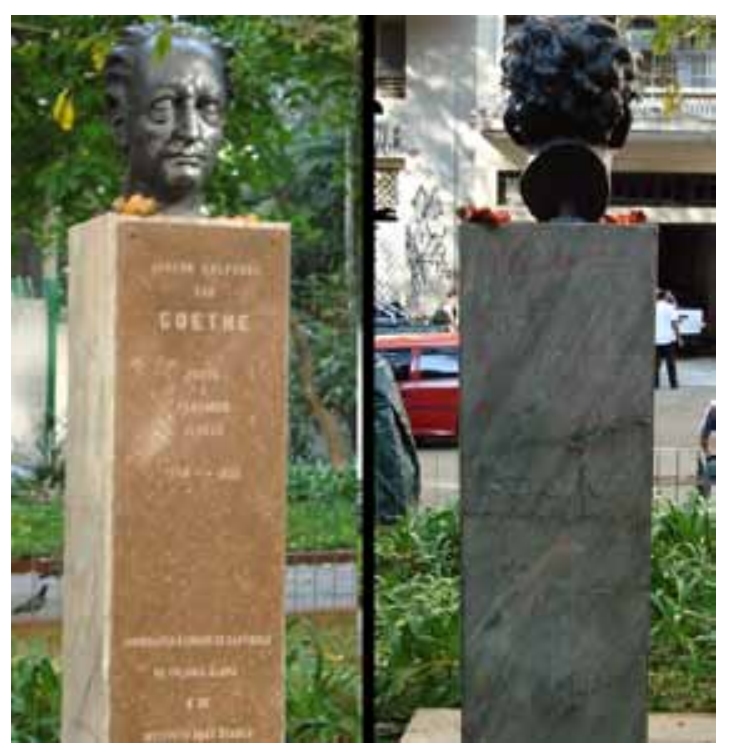

Figura 11. Göethe. Autor: Desconhecido; Tipologia: Cabeça; Material: Bronze, granito e mármore; Data de implantação: Desconhecida; Localização: Praça Dom José Gaspar

ser considerada situação ideal em termos de monumentos, mas que ajuda na conservação da obra. $\mathrm{O}$ pedestal está bastante manchado por resquícios de pichação, em tentativas de sua retirada.

Cervantes - nesse monumento recentemente restaurado, os dizeres da face frontal foram pintados em branco no pedestal de granito vermelho porfirítico. Desde 2005, quando foi adotada pelo programa municipal Adote um Monumento, apresenta-se em bom estado de conservação. A implantação de uma base móvel da Polícia Militar ao lado também ajuda nessa conservação. Até então, estava bastante pichada.

Chopin - a efígie é feita em bronze e está em bom estado de conservação. Seu pedestal é constituído por granito porfirítico de coloração avermelhada, com granulação média, e composto por quartzo, biotita e feldspato vermelho. Possui uma fissura na sua parte superior dianteira esquerda.

Ocorre sujidade na base do pedestal granítico devido aos respingos de lama durante as chuvas. Vestígios de pichação (grafitagem) são visualizados neste pedestal.

Dante Alighieri - A escultura foi executada por Bruno Giorgi enquanto ele esteve na Itália em 1955. O travertino da escultura foi doado pelo governo italiano e foi trazida à custa do instituto Ítalo-Brasileiro (hoje, Instituto Cultural Ítalo-Brasileiro) em nome da colônia italiana da cidade de São Paulo.

A estátua possui pequenos alvéolos, que são naturais devido ao tempo que esta ficou exposta às intempéries (data de implantação de 1955), porém o seu pedestal, além de possuir os mesmos alvéolos, perdeu o seu rejunte original. $\mathrm{Na}$ tentativa de restaurar o pedestal foi utilizada uma argamassa muito grossa, que esteticamente a deixou muito diferenciada.

Fraturas e fissuras são outras formas de alteração que se observam no pedestal. Vandalismo ocorre nesta obra na forma de pichações (grafitagem), mesmo depois de ter sido restaurada. Este é um problema crônico na cidade de São Paulo, sendo que todo monumento em que é executado trabalho de limpeza é quase que imediatamente pichado.

No detalhe da Figura 10 observa-se uma junta aberta com perda de rejunte no pedestal de travertino.

Göethe - A cabeça é constituída de bronze. O pedestal é composto de mármore de coloração cinza esverdeada, com placa frontal de granito vermelho porfirítico com fenocristais de feldspato. Este granito é semelhante ao granito comercialmente conhecido como Vermelho Bragança.

As formas de alteração observadas foram: fratura, mancha e pichação (grafitagem).

Mário de Andrade - a estátua do escritor brasileiro Mário de Andrade (Fig. 12), que foi um grande incentivador da arte de seu tempo, também está exposta na Praça Dom José Gaspar. Um ano após a sua morte, em 1946, ele foi homenageado com esta estátua nos jardins da Biblioteca Municipal. 


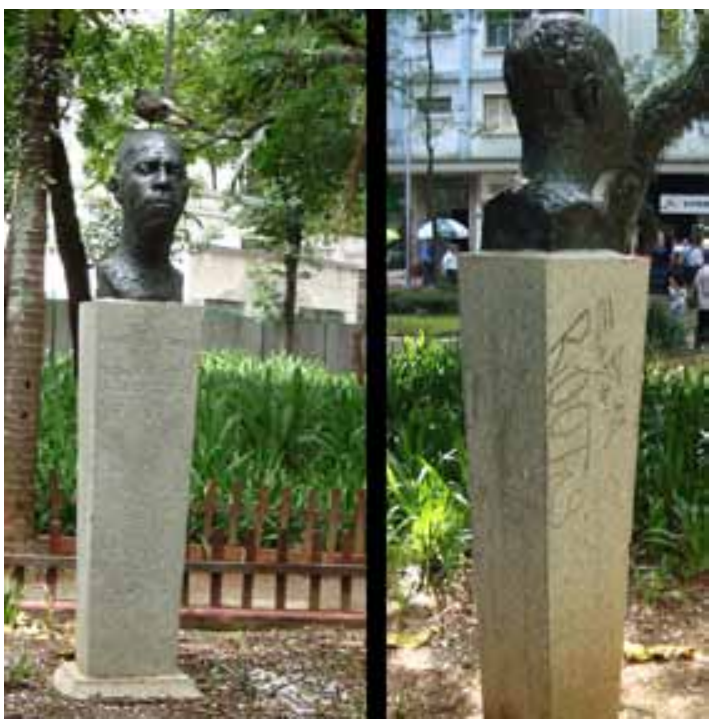

Figura 12. Mário de Andrade. Autor: Bruno Giorgi; Tipologia: Cabeça; Material: Bronze com pedestal em granito de coloração acinzentada, porfirítico com fenocristais de feldspato; Data de implantação: 1946; Localização: Praça Dom José Gaspar

A cabeça é constituída de bronze e apresenta um fino filme de pátina. O seu pedestal é constituído por biotita granito porfirítico de coloração acinzentada, com fenocristais de feldspato dispersos em uma matriz de granulação média composta por quartzo, biotita, feldspato e anfibólio.

Marcas de pichação (grafitagem) ainda podem ser observadas, mesmo depois da limpeza do pedestal. O monumento possui sujidade na parte inferior do seu pedestal de granito, pátina, perda de partes na forma de quinas quebradas, e ainda alteração cromática.

Na parte posterior do pedestal há uma coloração azulada devido a vestígios de pichação.

\section{Ponto $n^{0}$ 5: Largo da Memória}

Neste ponto localiza-se o monumento mais antigo da cidade de São Paulo: Obelisco da Memória (Fig. 13), constituído por um granito alterado. No século XIX, foi um dos pontos mais movimentados da cidade, onde os tropeiros faziam suas paradas quando chegavam na cidade.

A configuração atual data do ano de 1919.

Em 1991, foi tombado pelo CONPRESP (Conselho Municipal de Preservação do Patrimônio Histórico Cultural e Ambiental da Cidade de São Paulo).

As formas de alteração observadas no Obelisco da Memória foram: fissura, rompimento, mancha e pichação (grafitagem).

No detalhe da Figura 13 veem-se marcas de pichação na fonte que integra este obelisco.

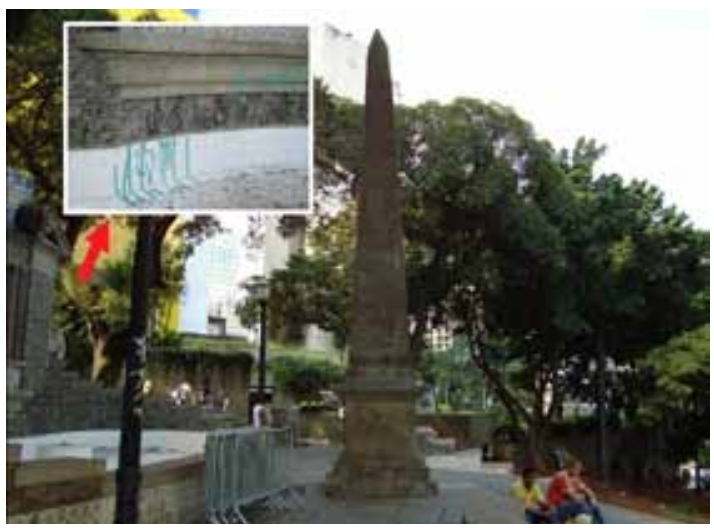

Figura 13. Obelisco da Memória. Autor: Daniel Pedro Mulher e Vicente Gomes Pereira; Tipologia: Obelisco; Material: Granito, muito alterado, de coloração acinzentada, equigranular de granulometria média; Data de implantação: 1814; Localização: Largo da Memória

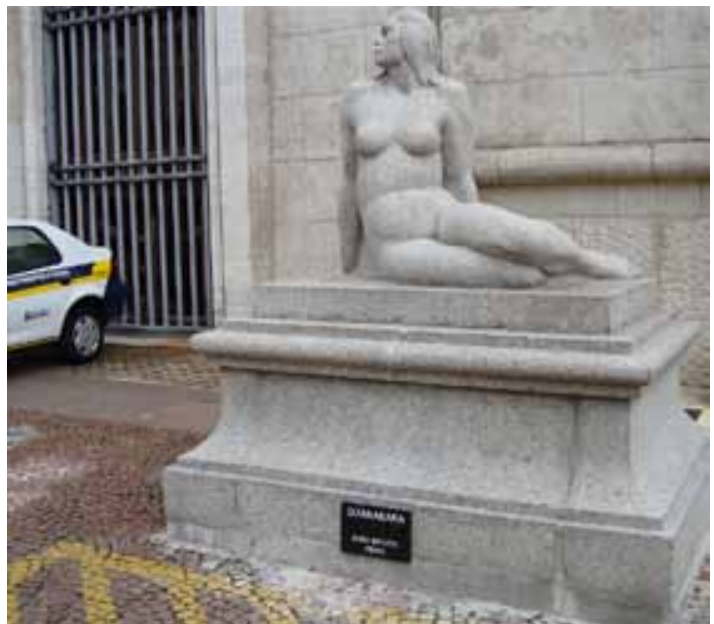

Figura 14. Guanabara. Autor: João Batista Ferri; Tipologia: Estátua; Material: Granito porfirítico com fenocristais de feldspato e coloração acinzentada; Data de implantação: 1949; Localização: Viaduto do Chá, defronte à Prefeitura Municipal; Localização anteriores: Vale do Anhangabaú, próximo ao acesso à Rua Líbero Badaró (1941)

\section{Ponto $\mathrm{n}^{0}$ 6: Viaduto do Chá}

Nesta parada observa-se a escultura Guanabara, confeccionada em granito (Fig. 14). Trata-se de uma mulher índia nua sentada sobre um pedestal retangular, com as pernas dobradas à esquerda do corpo. 
Tanto a índia como o pedestal foram confeccionados com o mesmo granito. Esta rocha é um biotita granito porfirítico de coloração acinzentada, com fenocristais de feldspato dispersos em uma matriz de granulação média constituída por quartzo, biotita e feldspato.

Apesar de apresentar perda de partes na forma de quinas quebradas e possuir pequenos vestígios de pichação (grafitagem) em sua parte posterior, a obra apresenta bom estado de conservação. Alteração cromática também ocorre na parte posterior do pedestal, devido a um grande enclave de biotita. $\mathrm{O}$ acabamento de seu rejunte, bem fino, aparenta de longe ao espectador, a impressão de que pedestal e estátua são peça única.

\section{Ponto $n^{0} 7$ : Praça Ramos de Azevedo}

Na Praça Ramos de Azevedo, ao lado do Teatro Municipal, encontra-se estátua em homenagem ao maestro brasileiro Antônio Carlos Gomes (Fig. 15), constituído por bronze, mármore e granito rosa.

A obra foi tombada pelo CONPRESP em 1992.

$\mathrm{O}$ arquiteto italiano Luiz Brizzollara foi o responsável por esta homenagem da colônia italiana ao primeiro centenário da independência do Brasil.

As formas de alteração observadas no Monumento a Carlos Gomes foram: alveolização, perda de partes, mancha, pichação (grafitagem) e sujidade.

\section{Ponto n 0 8: Largo do Paissandu}

No começo dos anos 1950, os membros do

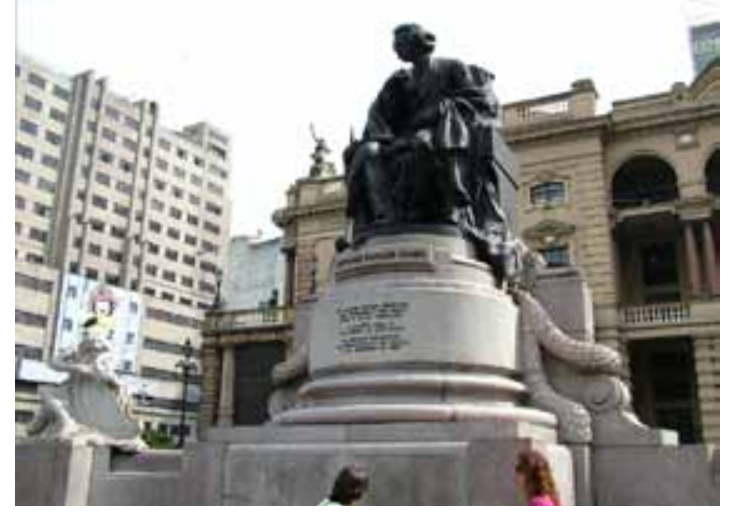

Figura 15. Monumento a Carlos Gomes. Autor: Luiz Brizzollara; Tipologia: Monumento; Material: Estátua de bronze e de mármore, e pedestal de granito de coloração rosa acinzentada, de granulometria média e equigranular; Data de implantação: 1922; Localização: Praça Ramos de Azevedo
Clube 220, entidade que reunia agremiações de população de negros do estado de São Paulo, empenharam-se na construção de um monumento a Mãe Preta. A escolha do Largo do Paissandu para acolher a homenagem à Mãe Preta deveu-se à presença da Igreja de Nossa Senhora do Rosário dos Homens Pretos e ao fato de ser aquele largo, desde a construção no

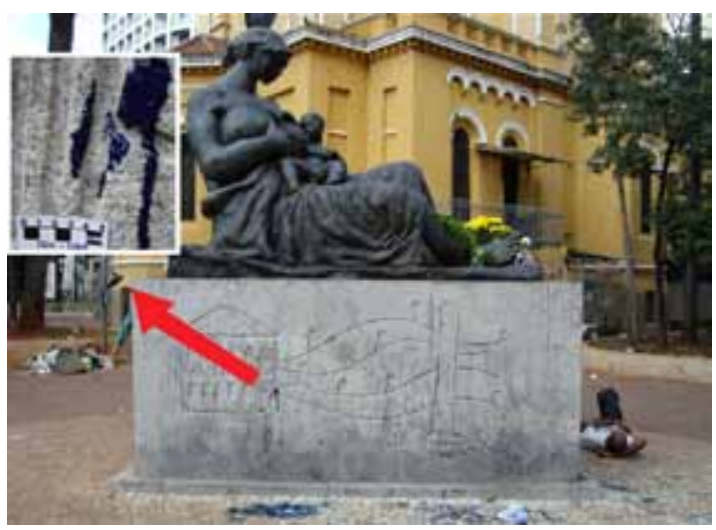

Figura 16. Mãe Preta. Autor: Júlio Guerra; Tipologia: Estátua; Material: Bronze, com base em granito de coloração acinzentada e granulometria variando de média a grossa; Data de implantação: 1955; Localização: Largo do Paissandu

começo do século XX, um ponto de referência para a comunidade afrodescendente de São Paulo.

Em 2004, foi tombada pelo CONPRESP.

O monumento é constituído por bronze e granito, e as formas de alteração observadas na Mãe Preta foram: rompimento, depósito, mancha, pichação (grafitagem) e sujidade.

No detalhe da Figura 16 é mostrada pichação com tinta azul.

\section{Considerações finais}

A finalidade da apresentação do presente roteiro é a de inserir as Geociências no contexto do patrimônio histórico e cultural, devido ao viés da presença de materiais geológicos na constituição dos monumentos aqui apresentados. Nesta inserção, destaca-se a participação dos geólogos, além da divulgação das Geociências, junto à comunidade no contexto do patrimônio cultural.

O roteiro aqui apresentado pode ser facilmente realizado por qualquer pessoa, e é mais um instrumento na divulgação do geoturismo pelo centro velho da cidade de São Paulo, revelando e identificando a variedade de rochas utilizadas nos monumentos indicados, e desta forma contribuin- 
do na divulgação das Geociências.

Informações mais detalhadas dos monumentos aqui apresentados podem ser encontradas em Reys et al. (2007), Augusto (2009) e Del Lama et al. (2009).

Infelizmente, de forma geral, o estado de conservação dos monumentos nem sempre é bom, tanto os propostos neste roteiro quanto os demais, não só pela alteração e degradação naturais, mas devido à falta de manutenção e principalmente devido ao vandalismo com depredações e pichações. Neste sentido, é necessária uma atuação mais incisiva dos órgãos responsáveis pelo patrimônio cultural e a instituição de uma educação patrimonial que se inicie nos ciclos básicos de ensino, buscando a valorização e preservação de nossa herança cultural, e acima de tudo, despertar a cidadania na população.

\section{Referências Biliográficas}

Augusto W.C.B. 2009. Caracterização geológica dos monumentos da cidade de São Paulo. São Paulo: Inst. Geoc. USP. 104 p. (Monogr. Trab. Formatura).

Baptista-Neto J.A., Smith B.J., McAllister J.J., Silva M.A.M., Castanheira F.S. 2006. Surface modification of a granite building stone in central Rio de Janeiro. An. Acad. Brasil. Ciênc., 78(2):317-330.

Costa A.G. 2009. Rochas e Histórias do Patrimônio Cultural do Brasil e de Minas. Rio de Janeiro: BemTe-Vi. 292p.

Del Lama E.A. 2006. Geologia e Herança Cultural. Rev. Bras. Geoc., 36(2):379-381.

Del Lama E.A. 2008. Instituto de Geociências da USP e Herança Cultural: Estreitando os Laços. Revista CPC (7:173-182. (Centro Preserv. Cult. USP). URL: : http://www.usp.br/cpc/v1/php/ wf07_revista_interna.php?id_revista $=11 \& i d$ _ conteudo $=14 \&$ tipo $=8$. Acesso 28.07.2010.

Del Lama E.A., Szabó G.A.J., Dehira L.K., Kihara Y. 2008. Impacto do intemperismo no arenito de revestimento do Teatro Municipal de São Paulo. São Paulo: Inst. Geoc. USP. Geologia USP - Série Científica, 8(1):75-86. URL: http://geologiausp. igc.usp.br/geologiausp/sc1/art.php? artigo $=703$. Acesso 28.07.2010.

Del Lama E.A., Dehira L.K., Reys, A.C. 2009. Visão geológica dos monumentos da cidade de São Paulo. Rev. Bras. Geoc., 39(3): 409-420. URL: http://ojs.c3sl.ufpr.br/ojs2/index.php/rbg/article/ view/12881/11163. Acesso 25.03.2010.
Fitzner B., Heinrichs K. 2004. Photo atlas of weathering forms on stone monuments. Geological Institute, RWTH Aachen University. Working Group "Natural Stones and weathering". URL: http:// www.stone.rwth-aachen.de. Acesso 29.07.2010.

Frascá M.H.B.O. 2003. Estudos experimentais de alteração acelerada em rochas graníticas para revestimento. São Paulo: Inst. Geoc. USP. 264p. (Tese Dout.).

ICOMOS. International Council on Monuments and Sites. 2008. Illustrated glossary on stone deterioration patterns. Champigny/Marne, França: ICOMOS. 80p. URL: http://www.international.icomos. org/publications/monuments_and_sites/15/pdf/ Monuments_and_Sites_15_ISCS_Glossary_ Stone.pdf. Acesso 25.03.2010.

Henriques F.M.A., Delgado Rodrigues J., AiresBarros L., Proença N. 2005. Materiais pétreos e similares. Terminologia das formas de alteração e degradação. Lisboa: LNEC. 39 p.

Philipp R.P., Di Benedetti V. 2007. Análise e avaliação da deterioração do revestimento de mármore da cúpula da catedral Metropolitana de Porto Alegre. Rev. Bras. Geoc., 37(4):650-659.

Pontes J.A.V. 2003. São Paulo de Piratininga: de pouso de tropas a metrópole. São Paulo: O Estado de São Paulo/Editora Terceiro Nome. 256p.

Reys A.C. 2006. Estado de conservação dos monumentos da cidade de São Paulo. São Paulo: Inst. Geoc. USP. 131 p. (Monogr. Trab. Formatura).

Reys A.C., Del Lama E.A., Dehira L.K. 2007. Monumentos da cidade de São Paulo: formas de alteração e conservação. Revista CPC, 5:93122. (Centro Preserv. Cult. USP). URL: http:// www.usp.br/cpc/v1/php/wf07_revista_interna. php?id_revista $=9 \& i d$ _conteudo $=22 \&$ tipo $=7$. Acesso 13.11.2008.

Silva M.E. da, Roeser H.M.P. 2003. Mapeamento de deteriorações em monumentos históricos de pedra-sabão em Ouro Preto. Rev. Bras. Geoc., 33(4):329-336.

Stern A.G., Riccomini C., Fambrini G.L., Chamani M.A.C. 2006. Roteiro geológico pelos edifícios e monumentos históricos do centro da cidade de São Paulo. Rev. Bras. Geoc., 36(4):704-711. URL: http://ojs.c3sl.ufpr.br/ojs2/index.php/rbg/article/ view/10995/7417. Acesso 26.03.2010.

Teixeira R.B., Silva, V.F., Barroso E.V. 2008. O martelo de Schmidt como ferramenta da avaliação da degradação de rochas de cantaria em prédios históricos. In: Congresso Brasileiro de Geologia de Engenharia e Ambiental, 12, Porto de Galinhas, 2008. Anais... São Paulo: ABGE. (CD-ROM). 